\title{
ORAL HEALTH PROFILE MAINTENANCE AMONG PATIENTS ATTENDING ISRA DENTAL COLLEGE.
}

1. BDS, MDS

Assistant Professor Oral Pathology Isra Dental College Hyderabad.

2. BDS, MDS

Assistant Professor Oral Pathology Isra Dental College/ Isra University Hyderabad.

3. BDS, MSc

Assistant Professor Operative Dentistry department of Isra Dental College/ Isra University Hyderabad.

4. BDS, MSc

Assistant Professor, Operative Dentistry department of Isra Dental College/ Isra University Hyderabad.

5. BDS, FCPS

Operative Dentistry department of LUMHS

6. BDS, MSc

Senior Lecturer, department of Periodontology of Isra Dental College/ Isra University Hyderabad.

Correspondence Address:

Dr. Uzma Tariq

Assistant Professor

Department of Oral Pathology

Isra Dental College Hyderabad.

mushtaqm1985@gmail.com

Article received on:

28/01/2020

Accepted for publication:

02/04/2020
Uzma Tariq ${ }^{1}$, Waqas Iqbal ${ }^{2}$, Mowaffaq Abdullmomen Al Absi ${ }^{3}$, Madiha Zaigum ${ }^{4}$, Sheba Ramzan ${ }^{5}$, Shafquat Hussain Khuwaja ${ }^{6}$

ABSTRACT... Objectives: To determine the oral health profile maintenance among patients attending Isra dental college Hyderabad. Study Design: Cross-sectional study. Setting: Oral pathology department of Isra University Hospital Hyderabad. Period: May 2017 February 2018. Material \& Methods: All the patients either of gender presented at dental OPD with any oral health problem were included in the study. Clinical examination was done among all patients. All the patients interviewed regarding duration of disease and maintenance of oral health including type of tooth paste, frequency of tooth paste and timing of tooth paste. All the data was entered in the profroma and analysed by SPSS version 20. Results: Total 539 patients were studied; their mean age was $28.34 \pm 33.12$ years. Females were found in majority 83.9\%. Sensitivity was among $36.2 \%$ patients, need of filling was among $42.9 \%$ patients, need of scaling was among $31.7 \%$. According to periodontal status, gums bleeding were in $13.2 \%$ patients, plaque formation was in $33.6 \%$ patients and calculus was in $10.0 \%$ patients. fluorosis was seen among $7.6 \%$ patients, malocclusion was in $13.7 \%$ patients, needs of Orthodontic treatment was in $14.7 \%$ patients and needs prosthodontics treatment was seen in $3.3 \%$ patients. According to oral health maintenance techniques Colgate, miswak and multiple tooth pastes uses were most common. Oral health status was insignificantly associated with frequency of oral health techniques, only needs of scaling was significantly higher among occasionally users of oral health techniques p-value 0.021. Conclusion: There was a lack of awareness amongst the people and their oral hygiene practice and dental visiting habits need to be addressed and modified.

Key words: Disease, Maintenance, Oral Health.

Article Citation: Tariq U, Iqbal W, Absi MAA, Zaigum M, Ramzan S, Khuwaja SH. Oral health profile maintenance among patients attending Isra Dental College. Professional Med J 2020; 27(5):1074-1078.

DOI: 10.29309/TPMJ/2020.27.05.4529

\section{INTRODUCTION}

Globally, oral infections are the major concern for public health and have a remarkable effect on people's everyday social lives and health. ${ }^{1}$

Globally, oral disorders influence 3.9 billion individuals. ${ }^{1,2}$ Worldwide, the most insecure are the deprived and poor people. Oral diseases have also become burden over Pakistani population. In Pakistan also less importance is given to oral health. ${ }^{3}$

The most common oral diseases are periodontal diseases and dental caries. Because of low importance given to oral health as well as oral health personnel scarcity i.e. oral health services scarcity to the population because $90 \%$ of the oral diseases are left untreated. ${ }^{3}$

Oral health implies to the state of having no facial and mouth pain, in addition to oral sores and infection, tooth loss, tooth decay, periodontal disease, throat or oral cancer, and further conditions, which restrict the abilities to speak, smile, chew, or bite, and adversely affect psychosocial health. ${ }^{4,5}$

Several systemic infections either arise in or could be inspected for in the buccal cavity at an initial stage, thus rapid development of the notion of systemic disorder screening and/or handling oral morbidity as a systematic disease manifestation in dental care. ${ }^{6}$ 
Pakistan faces major obstacles in terms of oral hygiene maintenance, as the majority of its people do not focus on improving oral health, is susceptible to addiction, has overlooked health problems, looking for self-medication, and often rural areas of residence, has limited healthcare access, which all makes people susceptible to bad oral health. ${ }^{6-9}$

The objective of good oral health is to eliminate or avoid tartar and plaque formation, to prevent parodontal disease and dental caries, and to reduce halitosis incidence. Several surveys show that most individuals do not realize the significance of good oral health and its relationship with overall Well-being. Because of its high incidence and major mechanism of social effect, oral disorder can be regarded as public health issue. ${ }^{3}$ Dental caries (Tooth decay) is a much common oral disorder. By acting on the poor oral hygiene, cariogenic diet, and dental awareness, tooth decay can be prevented. ${ }^{3}$

Few studies with small sample size has been found in literature. Therefore this big sample size study has been conducted to determine the oral health profile maintenance among patients attending Isra Dental College.

\section{MATERIAL \& METHODS}

This cross-sectional study was conducted at the Oral pathology department of Isra University Hospital Hyderabad from May 2017 February 2018. All the patients either of gender presented at dental OPD with any oral problem were included in the study. Patients with diagnosis of oral cancer and those were not agree to participate in the study were excluded. All the patients were randomly selected and clinical examination was done among all patients to assess the oral health profile. All the patients interviewed regarding duration of disease and maintenance of oral health including type of tooth paste, frequency of tooth paste and timing of tooth paste. All the data was entered in the proforma and analysed by SPSS version 20 . Frequency and percentage were calculated for qualitative variables and mean and SD were calculated for quantitative variables. Chi-square test was applied and $\mathrm{p}$-value $<0.05$ was considered as significant.

\section{RESULTS}

Total 539 patients were studied. Mean age of patients was $28.34+33.12$ years. Most common age group was 15-30 years. Females were found in majority $83.9 \%$ and males were $16.1 \%$. Table-I.

Sensitivity was among $36.2 \%$ patients, need of filling was among $42.9 \%$ patients, need of scaling was among $31.7 \%$. According to periodontal status, gums bleeding were in $13.2 \%$ patients, plaque formation was in $33.6 \%$ patients and calculus was in $10.0 \%$ patients. fluorosis was seen among $7.6 \%$ patients, malocclusion was in $13.7 \%$ patients, needs of Orthodontic treatment was in $14.7 \%$ patients and needs prosthodontics treatment was seen in 3.3\% patients. Table-II.

According to oral health maintenance techniques Colgate, miswak and multiple tooth pastes uses were most common. Mostly patients were seen with one and twice using oral health maintenance techniques $52.3 \%$ and $37.8 \%$ respectively. $7.1 \%$ had history of thrice maintenance and $2.8 \%$ had history of oral health maintenance occasionally. Table-III.

Oral health status was insignificantly associated with frequency of oral health techniques, only needs of scaling was significantly higher among occasionally users of oral health techniques p-value 0.021. Table-IV.

\begin{tabular}{|l|c|c|}
\hline \multicolumn{1}{|c|}{ Variables } & Frequency & Percent \\
\hline Age & & \\
\hline $15-30$ & 534 & $99.1 \%$ \\
\hline $31-45$ & 4 & $0.7 \%$ \\
\hline $46-60$ & 1 & $0.2 \%$ \\
\hline Total & 539 & $100.0 \%$ \\
\hline Gender & & \\
\hline Male & 47 & $16.1 \%$ \\
\hline Female & 539 & $83.9 \%$ \\
\hline Total & & $100.0 \%$ \\
\hline \multicolumn{2}{|c|}{ Table-I. Patient distribution according to age and } \\
gender $\mathbf{n = 5 3 9}$
\end{tabular}




\begin{tabular}{|c|c|c|}
\hline Variables & Frequency & Percent \\
\hline \multicolumn{3}{|l|}{ Sensitive } \\
\hline Yes & 195 & $36.2 \%$ \\
\hline No & 344 & $63.8 \%$ \\
\hline \multicolumn{3}{|l|}{ Need Filling } \\
\hline Yes & 231 & $42.9 \%$ \\
\hline No & 308 & $57.1 \%$ \\
\hline \multicolumn{3}{|l|}{ Need Scaling } \\
\hline Yes & 171 & $31.7 \%$ \\
\hline No & 368 & $68.3 \%$ \\
\hline \multicolumn{3}{|c|}{ Periodontal Status } \\
\hline Bleeding gums & 71 & $13.2 \%$ \\
\hline Plaque & 181 & $33.6 \%$ \\
\hline Calculus & 54 & $10.0 \%$ \\
\hline Normal & 233 & $43.2 \%$ \\
\hline \multicolumn{3}{|l|}{ Fluorosis } \\
\hline Yes & 41 & $07.6 \%$ \\
\hline No & 498 & $92.4 \%$ \\
\hline \multicolumn{3}{|l|}{ Malocclusion } \\
\hline Yes & 74 & $13.7 \%$ \\
\hline No & 465 & $86.3 \%$ \\
\hline \multicolumn{3}{|c|}{ Need Prosthodontic Treatment } \\
\hline Yes & 18 & $03.3 \%$ \\
\hline No & 521 & $96.7 \%$ \\
\hline \multicolumn{3}{|c|}{ Need Orthodontic Treatment } \\
\hline Yes & 79 & $14.7 \%$ \\
\hline No & 460 & $85.3 \%$ \\
\hline Table-II. Patier & $\begin{array}{l}\text { tribution accc } \\
\text { status } n=539\end{array}$ & oral heal \\
\hline
\end{tabular}

\begin{tabular}{|l|c|c|}
\hline $\begin{array}{c}\text { Oral Health Maintenance } \\
\text { Techniques }\end{array}$ & Frequency & Percent \\
\hline Close-up & 07 & 1.3 \\
\hline Colgate & 446 & 82.7 \\
\hline Dentonic & 01 & 0.2 \\
\hline Doctor & 06 & 1.1 \\
\hline English & 03 & 0.6 \\
\hline Forhen & 01 & 0.2 \\
\hline Medicam & 09 & 1.7 \\
\hline Miswak & 15 & 2.8 \\
\hline Mr White & 03 & 0.6 \\
\hline Multiple & 29 & 5.4 \\
\hline Pepsoden & 04 & 0.7 \\
\hline Sensodyne & 06 & 1.1 \\
\hline Sparkle & 09 & 1.7 \\
\hline Strawberry & 01 & 0.2 \\
\hline Total & 539 & 100 \\
\hline Frequency & & \\
\hline Once & 282 & 52.3 \\
\hline Twice & 204 & 37.8 \\
\hline Thrice & 38 & 7.1 \\
\hline Occasionally & 15 & 2.8 \\
\hline Total & 539 & 100 \\
\hline Table- & & \\
\hline
\end{tabular}

Table-III. Patient distribution according to types and frequency of toothpaste $n=539$

\begin{tabular}{|c|c|c|c|c|c|c|c|}
\hline \multirow{2}{*}{\multicolumn{2}{|c|}{ Oral Health Status }} & \multicolumn{4}{|c|}{ Frequency of Oral Health Techniques } & \multirow{3}{*}{$\begin{array}{c}\text { Total } \\
195\end{array}$} & \multirow{3}{*}{ P-Value } \\
\hline & & Once & Twice & Thrice & Occasionally & & \\
\hline \multirow{3}{*}{ Sensitive } & Yes & 101 & 76 & 15 & 3 & & \\
\hline & No & 181 & 128 & 23 & 12 & 344 & 0.573 \\
\hline & Total & 282 & 204 & 38 & 15 & 539 & \\
\hline \multirow{3}{*}{$\begin{array}{l}\text { Need } \\
\text { Filling }\end{array}$} & Yes & 119 & 90 & 13 & 9 & 231 & \\
\hline & No & 163 & 114 & 25 & 6 & 308 & 0.372 \\
\hline & Total & 282 & 204 & 38 & 15 & 539 & \\
\hline \multirow{3}{*}{$\begin{array}{l}\text { Need } \\
\text { Scaling }\end{array}$} & Yes & 119 & 90 & 13 & 9 & 231 & \\
\hline & No & 163 & 114 & 25 & 6 & 308 & 0.021 \\
\hline & Total & 282 & 204 & 38 & 15 & 539 & \\
\hline \multirow{5}{*}{$\begin{array}{l}\text { Periodontal } \\
\text { Status }\end{array}$} & Bleeding gums & 34 & 34 & 2 & 1 & 71 & \\
\hline & Plaque & 91 & 74 & 10 & 6 & 181 & \\
\hline & Calculus & 25 & 24 & 4 & 1 & 54 & 0.176 \\
\hline & Normal & 132 & 72 & 22 & 7 & 233 & \\
\hline & Total & 282 & 204 & 38 & 15 & 539 & \\
\hline \multirow{3}{*}{ Fluorosis } & Yes & 20 & 17 & 4 & 1 & 42 & 0.935 \\
\hline & No & 262 & 187 & 34 & 14 & 497 & \\
\hline & Total & 282 & 204 & 38 & 15 & 539 & \\
\hline \multirow{3}{*}{ Malocclusion } & Yes & 37 & 31 & 4 & 2 & 74 & \\
\hline & No & 245 & 173 & 34 & 13 & 465 & 0.852 \\
\hline & Total & 282 & 204 & 38 & 15 & 539 & \\
\hline \multirow{3}{*}{$\begin{array}{l}\text { Need Prosthodontic } \\
\text { Treatment }\end{array}$} & Yes & 8 & 9 & 1 & 0 & 18 & \\
\hline & No & 274 & 195 & 37 & 15 & 521 & 0.677 \\
\hline & Total & 282 & 204 & 38 & 15 & 539 & \\
\hline \multirow{3}{*}{$\begin{array}{l}\text { Need Orthodontic } \\
\text { Treatment }\end{array}$} & Yes & 38 & 33 & 4 & 4 & 79 & \\
\hline & No & 244 & 171 & 34 & 11 & 460 & 0.401 \\
\hline & Total & 282 & 204 & 38 & 15 & 539 & \\
\hline
\end{tabular}

Table-IV. Patient distribution according to types and frequency of toothpaste $n=539$ 


\section{DISCUSSION}

Oral health plays a pivotal role in the overall wellbeing and there is a variation in oral health status due to the changing trends and lifestyle. ${ }^{11}$ Oral diseases can be considered a public health problem duetotheirhigh prevalenceandsignificant social impact. ${ }^{12}$ Mostly young population are involved in poor health maintenance. In this study mean age of patients was $28.34+33.12$ years and females were in majority $83.9 \%$. These findings were similar to Aggnur $\mathrm{M}$ et $\mathrm{al}^{12}$ as most common age group was 25-34 years and females were most common. Dawani $\mathrm{N}$ et $\mathrm{al}^{13}$ reported that males was $41.6 \%$ and females was $58.4 \%$. Similar findings were reported by Narker JC et al. ${ }^{14}$ In this study sensitivity was among $36.2 \%$ patients, need of filling was among $42.9 \%$ patients, need of scaling was among $31.7 \%$. On other hand Aggnur $\mathrm{M}$ et $\mathrm{al}^{12}$ reported that $80.4 \%$ patients' needs periodontal treatment for removal of calculus and scaling. In this study according to periodontal status, gums bleeding were in $13.2 \%$ patients, plaque formation was in $33.6 \%$ patients and calculus was in $10.0 \%$ patients. RIZVI KF et al ${ }^{15}$ reported that periodontal diseases as calculus was in $54 \%$ patients, gums bleeding in $8 \%$ and poor oral hygiene observed $72 \%$.

In this study fluorosis was seen among $7.6 \%$ patients, malocclusion was in $13.7 \%$ patients, needs of Orthodontic treatment was in 14.7\% patients and needs prosthodontics treatment was seen in $3.3 \%$ patients. Similarly RIZVI KF et al ${ }^{15}$ reported that Fluorosis was among $13 \%$ patients. Bhagavatula $\mathrm{P}$ et $\mathrm{al}^{16}$ reported that dental fluorosis $27.8 \%$, which was higher as compared to this study.

In this study according to oral health maintenance techniques Colgate, miswak and multiple tooth pastes uses were most common. Hussain $\mathrm{P}$ et al ${ }^{17}$ reported that $31 \%$ people use brush and $20 \%$ Miswak, $6 \%$ use charcoal while $41 \%$ uses nothing to clean their teeth. Bangash MF et al ${ }^{18}$ reported that $23 \%$ individuals had history of miswak and $29 \%$ replied they using tooth brush for oral hygiene. In this study mostly patients were seen with one and twice using oral health maintenance techniques $52.3 \%$ and $37.8 \%$ respectively.
Similarly Aggnur $\mathrm{M}$ et $\mathrm{al}^{12}$ reported that mostly of the patients $43.2 \%$ patients used brush once a day. Bangash MF et $\mathrm{al}^{18}$ stated that most of the study participants were using tooth brush once and twice daily. In this study oral health status was insignificantly associated with frequency of oral health techniques, only needs of scaling was significantly higher among occasionally users of oral health techniques p-value 0.021 .

\section{CONCLUSION}

There was a lack of awareness amongst the people and their oral hygiene practice and dental visiting habits need to be addressed and modified. The present study emphasized the need of regular dental checkups and health education of people so sensitivity of teeth, tooth decay and periodontal problems due to poor oral hygiene can be addressed.

Copyright $@ 02$ Apr, 2020.

\section{REFERENCES}

1. Thapa P, Aryal KK, Mehata S, Vaidya A, Jha BK, Dhimal $M$ et al. Oral hygiene practices and their sociodemographic correlates among Nepalese adult: Evidence from non-communicable diseases risk factors STEPS survey Nepal 2013. BMC oral health. 2016 Dec; 16(1):105.

2. Marcenes W, Kassebaum NJ, Bernabé E, Flaxman A, Naghavi M, Lopez A. Global burden of oral conditions in 1990-2010: A systematic analysis. Journal of dental research. 2013 Jul; 92(7):592-7.

3. Khan F, Ayub A, Kibria Z. Knowledge, Attitude and practice about oral health among general population of Peshawar. J Dow Uni Health Sci 2013; 7(3): 117-121.

4. Furuta M, Yamashita Y. Oral health and swallowing problems. Current physical medicine and rehabilitation reports. 2013 Dec 1;1(4):216-22.

5. WHO. World Health Organization: Noncommunicable Diseases (NCD) Country Profiles, 2014 Pakistan. www. who.int/nmh/countries/paken.pdf (2017). Accessed October 2017.

6. Warsi I, Younus A, Rasheed A, Ahmed J, Mahida H, Hashmi R, Qureshi A. Oral health-related quality of life in patients with upper gastrointestinal and hepatic disorders in Pakistan: validation of the Oral Health Impact Profile-14 in the Urdu language. BDJ open. 2018 Apr 27;4(1):17036. 
7. Niaz MO, Naseem M, Siddiqui SN, Khurshid Z. An outline of the oral health challenges in "Pakistani" population and a discussion of approaches to these challenges. JPDA. 2013 Jul; 21 (3).

8. Shekarchizadeh H, Khami MR, Mohebbi SZ, Ekhtiari H, Virtanen JI. Oral health of drug abusers: A review of health effects and care. Iranian journal of public health. 2013 Sep;42(9):929.

9. Harchandani N. Oral health challenges in Pakistan and approaches to these problems. Pak. Oral Dent. J. 2012;32:497-501.

10. Panagakos FS, Migliorati CA. Concepts of oral hygiene maintenance that would apply for the different groups of patients. InDiagnosis and Management of Oral Lesions and Conditions: A Resource Handbook for the Clinician 2014; 19;1-17.

11. Geethapriya PR, Asokan S, Kandaswamy D. Comparison of oral health status and knowledge on oral health in two age groups of schoolchildren: A cross-sectional study. International journal of clinical pediatric dentistry. 2017 Oct; 10(4):340.

12. Aggnur M, Garg S, Veeresha KL, Gambhir RS. Oral health status, treatment needs and knowledge, attitude and practice of health care workers of Ambala, India. A Cross-sectional Study. Annals of medical and health sciences research. 2014; 4(5):67681.
13. Dawani N, Nisar N, Khan N, Syed S, Tanweer N. Prevalence and factors related to dental caries among pre-school children of Saddar town, Karachi, Pakistan: A cross-sectional study. BMC oral health. 2012 Dec 1; 12(1):59.

14. Narker JC, Rise J. Distribution of oral health behavior in adults. Community Dent Oral Epidemiol 2007; 49 (1): 9-13.

15. RIZVI KF, Bashir R. Oral Health status in Public School children. Pakistan Oral \& Dental Journal. 2015 Dec 1; 35(4).

16. Bhagavatula P, Levy SM, Broffitt B, Weber $\square$ Gasparoni $\mathrm{K}$, Warren $\mathrm{JJ}$. Timing of fluoride intake and dental fluorosis on late-erupting permanent teeth. Community dentistry and oral epidemiology. 2016 Feb; 44(1):32-45.

17. Hussain $P$, Anjum $Q$, lqbal $Z$. Oral hygiene awareness among the patients visiting the dental centers of a rural area of the Province Punjab, Pakistan. Biomedica. 2017 Mar 1; 33(1).

18. Bangash MF, Khan J, Hanif A. Oral hygiene practice and awareness among Pakistanis in Riyadh, Saudi Arabia. Pakistan Oral Dental J. 2013; 33:2.

\begin{tabular}{|c|c|c|c|}
\hline \multicolumn{4}{|c|}{ AUTHORSHIP AND CONTRIBUTION DECLARATION } \\
\hline Sr. \# & Author(s) Full Name & Contribution to the paper & Author(s) Signature \\
\hline 1 & Uzma Tariq & Data collection. & \\
\hline 2 & Waqas lqbal & Manuscript writing. & \\
\hline 3 & Mowaffaq Al Absi & Manuscript review. & $A-$ \\
\hline 4 & Madiha Zaigum & Data analysis. & $1-7$ \\
\hline 5 & Sheba Ramzan & Manuscript writing. & $x^{2}-$ \\
\hline 6 & Shafqat Husain Khuwaja & Review of literature. & $8+2 \%$ \\
\hline
\end{tabular}

